RBEn, 31 : 101-113, 1978

\title{
PROCESSO DE ENFERMAGEM ORIENTADO PARA OS PROBLEMAS DO PACIENTE: INICIAÇAO DE ENSINO EM FUNDAMENTOS DE ENFERMAGEM
}

\author{
Autoras, : \\ Dra. Nara Sena de Paula ** \\ Maria Margarida da Cunha Gonçalves * * *:k \\ Tamara Iwanov Cianciarullo *** \\ Rosa Áurea Quintella Fernandes* \\ Maria Romana Friedlander *** \\ Maria Coeli Campedelli * \\ Edna Aparecida Moura Arcuri **** \\ Neide Valdez dos Santos *
}

$\mathrm{RBEn} / 12$

PAULA, N.S. e colaboradoras - Processo de enfermagem orientado para os problemas do paciente: iniciaçāo de ensino em fundamentos de enfermagem. Rev. Bras. Enf.; DF, 31 : 101-113, 1978.

O COFEN está elaborando um anteprojeto de lei que regulamentará a Enfermagem e, segundo este, as enfermeiras terāo que desempenhar sua funçāo de assišência ao paciente com utilização de uma metodologia própria que é o Processo de Enfermagem.

Esta metodologia já tem sido ensinada aos alunos da EEUSP, porém neste ano, 1977, desenvolvemos em Fundamentos de Enfermagem uma nova abordagem ao assunto, iniciando o ensino do Processo de Enfermagem orientado para os problemas do paciente. Este ensi- no teria que ser continuado nas outras disciplinas de enfermagem do currículo, porém, como iniciaçāo, achamos oportuno publicar a nossa experiência para que possa ser testada e desenvolvida em outras situaçōes de ensino.

As enfermeiras vêm sendo assediadas por idéias e pelo próprio desenvolvimento tecnológico e científico para melhorar a eficiência das suas atividades junto ao seu cliente.

Aqui no Brasil, Dra. Wanda de Aguiar Horta (1971) vem estudando e aprofundando uma metodologia do processo de

(*) Equipe de Fundamentos de Enfermagem da EEUSP.

(**) Doutora em Enfermagem.

$(* * *)$ Mestres em Enfermagem. 
PAULA, N.S. e colaboradoras - Processo de enfermagem orientado para os problemas do paciente: iniciaçāo de ensino em fundamentos de enfermagem. Rev. Bras. Enf.; DF, 31 : 101-113, 1978.

enfermagem baseada nas necessidades humanas básicas que tem influenciado e estimulado outros profissionais a desenvolverem suas idéias.

Outros estudos têm sido desenvolvidos no Brasil a respeito da sistematização da assistência de enfermagem como os de PAULA e colab. (1967), FRIEDLANDER (1973), CIANCIARULLO e colab. (1974), PAIM, (1975).

No exterior inúmeros trabalhos têm sido feitos sobre o asunto como: CARRIERI (1971), CARLSON (1972), YURA (1973), MITCHELL (1973).

Atualmente verifica-se a tendência a se dar ênfase aos problemas do paciente, mais do que a seu diagnóstico ou qualquer outro enfoque à sua problemática. Surge na literatura média a abordagem dos prontuários orientados para os problemas dos pacientes como o faz WEED (1971) chamando-os de POMR ou seja, "Problem Oriented Medical Record".

Ao elaborarmos o planejamento da utilizaçāo do Processo de Enfermagem em Fundamentos de Enfermagem, partimos do pressuposto de que é uma atividade muito complexa, desenvolvida gradativamente no aluno de Enfermagem e, portanto, precisando ser iniciada como um primeiro passo na escala desse desenvolvimento.

Consideramos que seria por demais difícil para o aluno de Fundamentos de Enfermagem, baseadas em experiências anteriores, classificar os problemas do paciente em termos das necessidades afetadas, fazer o diagnóstico de enfermagem global do paciente e dar assistência de enfermagem a partir deste enfoque. Pareceu-nos que seria mais fácil ao aluno iniciante registrar os problerıas básicos de enfermagem que surgissem com a aplicaçāo do Histórico de Enfermagem simplificado, dar assistência direta a cada um destes problemas de "per si" e acompanhar a evolução e resoluçāo de cada um destes problemas isoladamente. Como o aluno iria cuidar individualmente de cada paciente, seria capaz de relacionar os problemas entre si e perceber as implicaçōes de uns sobre outros.

Assim, em linhas gerais, o esquema de ensino seguido foi o de fundamentação teórica sobre o assunto, manuseio e preenchimento em classe dos instrumentos de trabalho sob a forma de impressos que seriam utilizados na prática e estágio supervisionado de 9 semanas com aplicação sistemática da metodologia proposta.

\section{COMO FOI INTRODUZIDA A PARTE TEÓRICA DO PROCESSO DE ENFER- MAGEM PARA OS ESTUDANTES}

Fundamentos de Enfermagem sendo a primeira disciplina do tronco profissional oferece aos alunos a oportunidacle de estabelecerem e desenvolverem os primeiros contatos com pacientes hospitalizados. Aproveitamos, então, esta oportunidade para iniciar com o grupo de alunos o aprendizado sobre 0 processo de enfermagem.

Nas aulas iniciais desta disciplina, os estudantes receberem noçōes sobre 0 processo de enfermagem num total aproximado de 10 horas aula. Neste período foram organizados pequenos grupos de estudo para leitura e discussão de bibliografia escolhida e pertinente ao asunto. Nas duas últimas horas aulas, foi-lhes apresentado um resumo das vantagens, utilizaçāo e fases do process so. Ainda, nesta ocasiāo, foram discutidos, com a classe, os principais aspectos dessa metodologia e as dúvidas dos alunos. Verificou-se, pelo número de perguntas e pelo interesse nos debates, que o estudo motivou bastante o grupo.

Uma semana antes do trabalho de campo (estágio) ser inicado, foram utilizadas 12 horas para preparar os estu- 
PAULA, N.S. e colaboradoras - Processo de enfermagem orientado para os problemas do paciente: iniciaçāo de ensino em fundamentos de enfermagem. Rev. Bras. Enf.; DF, 31 : 101-113, 1978.

dantes no manuseio dos impressos e desenvolvê-los na aplicação prática do processo de enfermagem. Nas primeiras 2 horas-aula deste período foi feita uma recapitulação da filosofia e etapas dó processo pois houve uma defasagem de cerca de dois meses entre as aulas iniciais e a utilizaçāo prática do mesmo. Nas 4 horas-aula seguintes foram apresentados os impressos que seriam usados durante o estágio e as normas de preenchimento e utilização deles. Nas 6 horas finais foram apresentados históricos de enfermagem preenchidos hipoteticamente e, em reuniōes de pequenos grupos, os alunos desenvolveram todas as demais etapas baseados nos dados apresentados nestes históricos.

As normas de preenchimento e utilizaçāo dos impressos foram o produto de várias reuniōes da equipe de docentes desta disciplina para discussão, estudo e tomada de posição da forma de como se iria orientar o estudante, durante todo o periodo de trabalho de campo. Estas reuniōes permitiriam, também, uma certa homogeneidade da atuação da equipe, indispensável à segurança da própria docente e ao aproveitamento do estudante.

\section{MATERIAL E MÉTODO}

A aplicação do processo de Enfermagem orientado para os problemas dos pacientes foi realizada no Hospital das Clínicas da Faculdade de Medicina da U.S.P., no período de $2 / 5 / 77$ a $30 / 6 / 77$, em clínicas médicas e cirúrgicas.

Participaram 7 docentes na supervisāo direta dos 78 alunos, uma docente responsabilizou-se pela coordenaçāo geral do trabalho, dos estudos paralelos e do acompanhamento dos Estudos sobre $\mathrm{Pa}$ ciente apresentados em classe.

No estágio, cada aluno cuidou de 1 a 3 pacientes usando o Processo de Enfermagem orientado para os problemas do paciente, com supervisāo diária e direta de um docente para cada 6 ou 7 alunos.

Para ser possível a formaçāo destes pequenos grupos de alunos, condiçāo indispensável para o sucesso do programa, a classe de 78 alunos foi dividida em dois grupos que se alternavam em estágio: um dos grupos (grupo $X$ ) foi para 0 campo às 2.as e 5.as feiras e o outro grupo (grupo $Y$ ) às 3.as e 6.as feiras. Cada um destes pequenos grupos foi acompanhado por uma docente.

As docentes de Fundamentos de Enfermagem, ficaram fixas e muma unidade do hospital, com a qual já estavam habituadas e foram ao estágio às 2.a8, 3.as, 5.as e 6.as feiras. Durante as nove semanas a docente recebeu o mesmo sub-grupo às 3.as e 6.as feiras, as 4.as feiras foram reservadas para reuniōes das docentes da disciplina.

As atividades diárias no campo tinham a duraçāo de 5 horas, reservando-se a última hora para avaliaçāo e troca de experiência de cada sub-grupo com as respectiva docente. Além disso, cada docente reunia os seus 2 sub-grupos no final de cada semana para discutirem os problemas dos pacientes a fim de assegurarem a continuidade da assistência de enfermagem.

Foram previstos estudos dirigidos, leituras e pesquisas no campo, para os alunos que se alternavam em estágio. Aos sábados eram realizadas reuniōes de toda a classe para discussão, orien:taçāo e apresentaçāo de relatórios finais desses estudos paralelos, com a participação das docentes responsáveis pelos assuntos.

Considerando o fato da classe ter sido dividida em dois grupos e os alunos alternarem-se no estágio, levantou-se o problema da possibilidade de ser descontínua a experiência do aluno e a assistência ao paciente. Esta forma de descontinuidade do aluno em estágio foi bastante discutida, porém a decisāo fí- 
PAULA, N.S. e colaboradoras - Processo de enfermagem orientado para os problemas do paciente: iniciação de ensino em fundamentos de enfermagem. Rev. Bras. Enf.; DF, 31 : 101-113, 1978.

nal baseou-se no pressuposto de que o Processo de Enfermagem garante uma continuidade de cuidados ao paciente ainda que o elemento da equipe de enfermagem nāo seja o mesmo todos os dias. Para assegurar ao paciente o minimo de mudanças de pessoas responsáveis por ele, os alunos cuidavam dos pacientes aos pares, sempre que possivel, isto é, um aluno do grupo $\mathbf{X}$ e outro do grupo $Y$ eram responsáveis sempre pelo mesmo paciente e, portanto, de todo seu prontuário de enfermagem.

A escolha dos pacientes procurou atender as oportunidades para execuçāo de cuidados, motivaçāo dos alunos e facilidade de supervisāo.

\section{Instrumentos utilizados}

Para facilitar o manuseio dos impressos utilizados no cuidado de cada paciente, os mesmos foram colocados em uma pasta que foi denominada "prontuário de enfermagem do paciente".

Cada prontuário constou dos seguintes impressos:

1 - Histório de Enfermagem III (HORTA, 1976)

2 - Mapa de problemas do paciente

3 - Plano de Cuidados

4 - Evolução do paciente

Para uso das docentes foi utilizado o impresso "Relaçāo de pacientes com Histórico de Enfermagem I" (Anexo 1). Histórico de Enfermagem III (Anexo 1)

Em linhas gerais constou dos dados de identificação do paciente; percepçōes e expectativas; atendimento das necesdades básicas; exame físico; o que gostaria de perguntar; impressōes do entrevistador e dados clínicos de interesse para a enfermagem.

O preenchimento deste impresso foi orientado seguindo as normas:

- Identificar o impresso com nome e número do leito do paciente.
- Procurar levantar todos os dados indicados pelo impresso.

- Registrar as informaçōes colhidas no lado direito da folha.

- Utilizar uma linguagem objetiva e concisa.

- Coletar os dados no primeiro contato formal com o paciente. Completálos durante a execução dos cuidados ou sempre que surgissem novas informaçōes.

- Fazer o exame físico durante o banho no leito ou durante cuidados de higiene. Caso não haja essa oportunidade, examinar detalhadamente 0 paciente em ocasiāo específica para isto.

- Sublinhar todos os problemas do paciente identificados no histórico.

\section{Mapa de Problemas (Anexo 2)}

Este impresso constou dos dados de identificaçāo do paciente; número do leito, data de internaçāo, e colunas para data, número e listagem dos problemas levantados, açāo da Enfermagem, data da abordagem, data da solução.

Para o preenchimento e utilizaçāo deste mapa as normas estabelecidas foram:

- Preencher imediatamente após os primeiros problemas terem sido identificados.

- Listar os problemas identifcados no histórico e numerá-los de acordo com a ordem de identificaçāo.

- Determinar uma ou mais açōes de enfermagem para cada problema levantado na coluna correspondente.

- Repetir no mapa o problema do paciente, caso tenha que ser revisado ou acrescentadas novas açōes de enfermagem, conservando o mesmo número que o caracterizou na primeira vez. 
PAULA, N.S. e colaboradoras - Processo de enfermagem orientado para os problemas do paciente: iniciaçăo de ensino em fundamentos de enfermagem. Rev. Bras. Enf.; DF, 31 : 101-113, 1978.

- Anotar a data do início da execução da açāo de enfermagem na coluna "Data da Abordagem" e a data de resoluçāo de cada problema na coluna "Data da Soluçāo".

- Rever e atualizar, diariamente, o "mapa de problemas".

\section{Plano de Cuidados (Anexo 3)}

Constou de identificação do paciente e colunas para data, cuidados de enfermagem e horário.

As normas para sua utilização e preenchimento foram:

- Datar o plano na coluna correspondente.

- Redigir o plano de cuidados após o preenchimento do mapa de problemas ou após a atualização deste e do histórico de enfermagem.

- Elaborar o plano de forma a individualizar o paciente.

- Elaborar o plano baseando-se nos problemas levantados e nas prioridades estabelecidas.

- Planejar cuidados que solucionem esses problemas e que previnam ou detectem outros problemas.

- Redigir a lista de cuidados a serem dispensados ao paciente seguindo a ordem:

$1 .^{\circ}$ - controles necessários

2. - cuidados referentes à higiene, alimentação, medicaçāo e tratamentos

3. ${ }^{\circ}$ - observaçāo de sinais e sintomas

$4.0^{\circ}$ - verificaçōes sobre a eficiência dos tratamentos e cuidados

5. - orientaçōes a serem ministradas

6..$^{\circ}$ - encaminhamentos

- Colocar o horários conveniente após cada item da prescriçāo.
- Elaborar o plano com um número praticável de cuidados (quanto ao tempo e condiçōes da unidade) para ser eexcutado no período das 7 às 11 horas.

- Assinar o plano imediatamente após a prescriçāo do último cuidado.

- Estudar detalhadamente o plano antes do início da execução dos cuidados. No caso de qualquer dúvida, discutí-la com a docente.

- Modificar o plano, caso fosse necessário, e adaptá-lo às condiçōes exigidas pelo paciente no momento da prestação dos cuidados.

\section{Evolução do Paciente (Anexo 4)}

Constou de identificação do paciente, colunas destinadas a data e a rubrica do aluno. A orientação ao seu preenchimento e utilização obedeceu às normas:

- Fazer, diariamente, a evoluçāo do paciente após os cuidados terem sido prestados.

- Datar e assinar todas evoluçōes.

- Elaborar a evoluçāo com o seguinte conteúdo:

1. ${ }^{\circ}$ - dados sobre a possibilidade de execuçāo ou não do plano de cuidados e, se fosse o caso, as causas da nāo execução;

2. - itens que nāo foram executados e motivo;

3. ${ }^{\circ}$ - evolução dos problemas do paciente;

4. ${ }^{\circ}$ - novos fatos acerca do paciente;

5..$^{\circ}$ - visão global do seu estado.

- Ler atentamente a evoluçāo do dia anterior antes do início da execuçāo da prestação dos cuidados.

Relação de pacientes com Histórico de Enfermagem III (Anexo 5)

Constou de colunas destinadas a ordem de entrada do paciente no estudo, 
PAULA, N.S. e colaboradoras - Processo de enfermagem orientado para os problemas do paciente: iniciaçāo de ensino em fundamentos de enfermagem. Rev. Bras. Enf.; DF, 31 : 101-113, 1978.

nome do paciente, número do leito, registro, data da entrada do paciente no estudo, data da saída do paciente do estudo, nome da aluna responsável e observaçōes.

A docente deveria atualizar diariamente este impresso.

No desenvolver do estudo estabeleceuse também que as docentes deveriam revisar diariamente o plano das estudantes para aquele dia, e sempre que possível revisar os prontuários de enfermagem discutindo-se com os alunos.

\section{EXEMPLO DE PARTES DE UM PRONTUARIO DE ENFERMAGEM}

Histórico de enfermagem:

Nome: .........; Registro: ..... ....... ; Diagnóstico médico: Estenose Cáustica do esôfago; 22 anos, sexo feminino; loira, solteira, ginásio completo; estudava e trabalhava em fábrica de caixas; católica praticante (missa aos sábados e domingos); nasceu no interior do estado de Sāo Paulo e mora em Curitiba.

Foi admitida no dia 02-02-77. Começou o tratamento em um Hospital de Curitiba de onde foi transferida para o H.C.

Preocupa-se com sua cura e com a mãe. Tem medo da cirurgia. Nāo gosta muito de médico à sua volta. Há muita troca de médico. Sabe que tem que fazer esofagocoloplastia em dois tempos. Está informada de que corre grande risco na cirurgia. Em setembro completa três anos de tratamento. Passa mais tempo internada do que em casa.

Dorme cerca de nove horas por dia. Até 1972 fazia educaçāo física na escola. Jogou basquete mesmo depois de sair da escola. Antes do tratamento comia arroz, bife, ovos, salada. Gosta de batata frita. Três lanches, almoço e jantar.
Agora nảo pode comer nada, só dieta líquida. As vezes fica uma semana sem beber água. Evacua duas a três vezes por semana. Tomava banho de banheira duas vezes por dia. No hospital toma um banho de manhã e outro à noite.

Mora na cidade, casa de alvenaria, água encanada, luz elétrica, gás, quintal com jardim, cozinha, sala, três quartos, um banheiro. Possui cachorro (um). Tem na casa moscas e pernilongos.

Gosta de escrever e ler, educação física. Quer ser fotógrafa. Fazia bichinhos de lā. Gosta de trabalhos manuais.

Nunca teve relaçōes sexual.

Tem māe, nove irmās (oito casadas) três irmāos (um casado). O pai morreu quando tinha oito anos. E filha mais nova. A māe trabalha como lavadeira e cuida de três sobrinhos, sendo que o que tem onze anos cuida dos outros dois menores que ele.

Nâo acredita no cuidado médico. Estudou num livro à respeito da doença. Quer ficar boa.

Observaçōes: paciente com aparente boa vontade para responder às perguntas, expressando-se facilmente, com fluência e segurança no que diz.

Em abordagem posterior:

Deixaremos de transcrever literalmente a problemática que levou a paciente a tomar "Diabo Verde" por se tratar de relato confidencial que poderia levar à identificaçāo da paciente e quebra do sigilo profissional.

De vez em quando fumava escondido da mãe. Teve varicela, sarampo e caxumba. Era vacinada todo ano na escola, mas não sabe para que. Foi vacinada três vezes para meningite. Depois da moléstia atual vai ao dentista de três em três meses. Antes tinha ido duas vezes ao médico.

Gosta de fazer amizades e ajudar os funcionários. Não gosta de alguns funcionários e pacientes, mas não dá de- 
PAULA, N.S. e colaboradoras - Processo de enfermagem orientade para os problemas do paciente: iniciação de ensino em fundamentos de enfermagem. Rev. Bras. Enf.; DF, 31 : 101-113, 1978.

monstração disso. Não gosta da Enfermeira-chefe que nāo a deixou receber visitas de uma funcionária da ORL (Clínica de Otorrinolaringologia). E muito nervosa, (chora, grita, joga as coisas no chāo quando pensa que não vai sarar). Fica nervosa às terças e quinta-feiras depois da visita médica, porque ouve tudo, entendendo quase tudo que eles dizem, e não consegue deixar de ouvir. Preocupa-se em cortar o esterno e com as cicatrizes e cicatrizaçāo.

Exame físico:

Aspecto geral bom; expressāo facial normal; conversa muito contactuando bem como o meio, tem noção do tempo e espaço. Boa postura, locomoção normal. Vestuário próprio.

Peso: $55400 \mathrm{~kg}$.

Altura: $1,60 \mathrm{~cm}$.

Sinais Vitais: PA: $9 / 5,5$

T: $36.7 \quad$ P: $78 \quad$ R: 20

Cabeça: cabelos em bom estado de higiene, boa mobilidade.

Ouvidos: n.d.n. (nada digno de nota).

Nariz: fossa nasal semi-obstruída com saída de um fio-guia para dilataçāo do esôfago.

Boca: mucosa integra; possui prótese superior. Arcada dentária inferior com presença de cáries nos molares, pré-molares e incisivos.
Membros Superiores: pele íntegra em bom estado de limpeza. Pele áspera nos cotovelos e necessitando de melhor higiene. Pelos nas axilas (faz tricotomia toda semana). Músculos em boas condiçōes e rede venosa regular. Possui cicatriz na face interna do braço, próxima à articulação, apresentando um ponto que, segundo a paciente, infecciona com freqüência.

Pescoço: mobilidade boa e sem lesōes. Não posui gânglios infartados.

Mamas: n.d.n.

Tórax: n.d.n.

Abdomem: sujidade na regiāo umbilical. Apresentando manchas que a paciente refere serem de esparadrapo por ser alérgica. Possui gastrostomia aberta.

Tronco-dorsal: torax- - n.d.n.

$$
\text { lombo-sacro - n.d.n. }
$$

regiāo anal - n.d.n.

Nádegas: musculatura entrófica, manchas escuras que a paciente informa terem sido causadas por lesōes na infância.

Membros Inferiores: pele ressecada, tricotomia uma vez por semana.

Genitais externos: aspecto normal.

Dados clínicos de interesse: infecção urinária por Escherichia coli, (cultura 16/04/77). 
PAULA, N.S. e colaboradoras - Processo de enfermagem crientado para os problemas do paciente: iniciação de ensino em fundamentos de enfermagem. Rev. Bras. Enf.; DF, $31: 101-113,1978$.

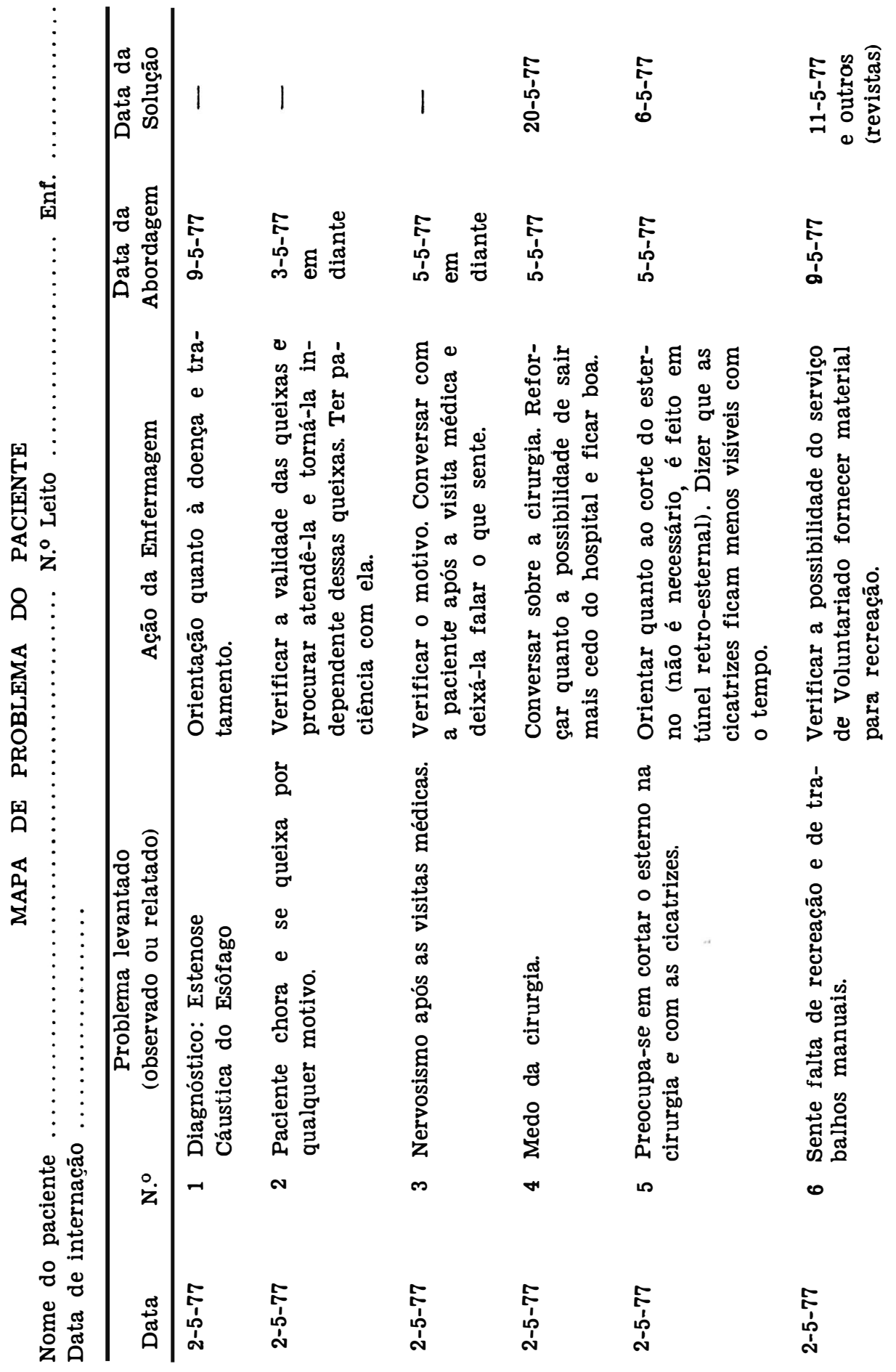


PAULA, N.S. e colaboradoras - Processo de enfermagem orientade para os problemas do paciente: iniciaçāo de ensino em fundamentos de enfermagem. Rev. Bras. Enf.; DF, 31 : 101-113, 1978.

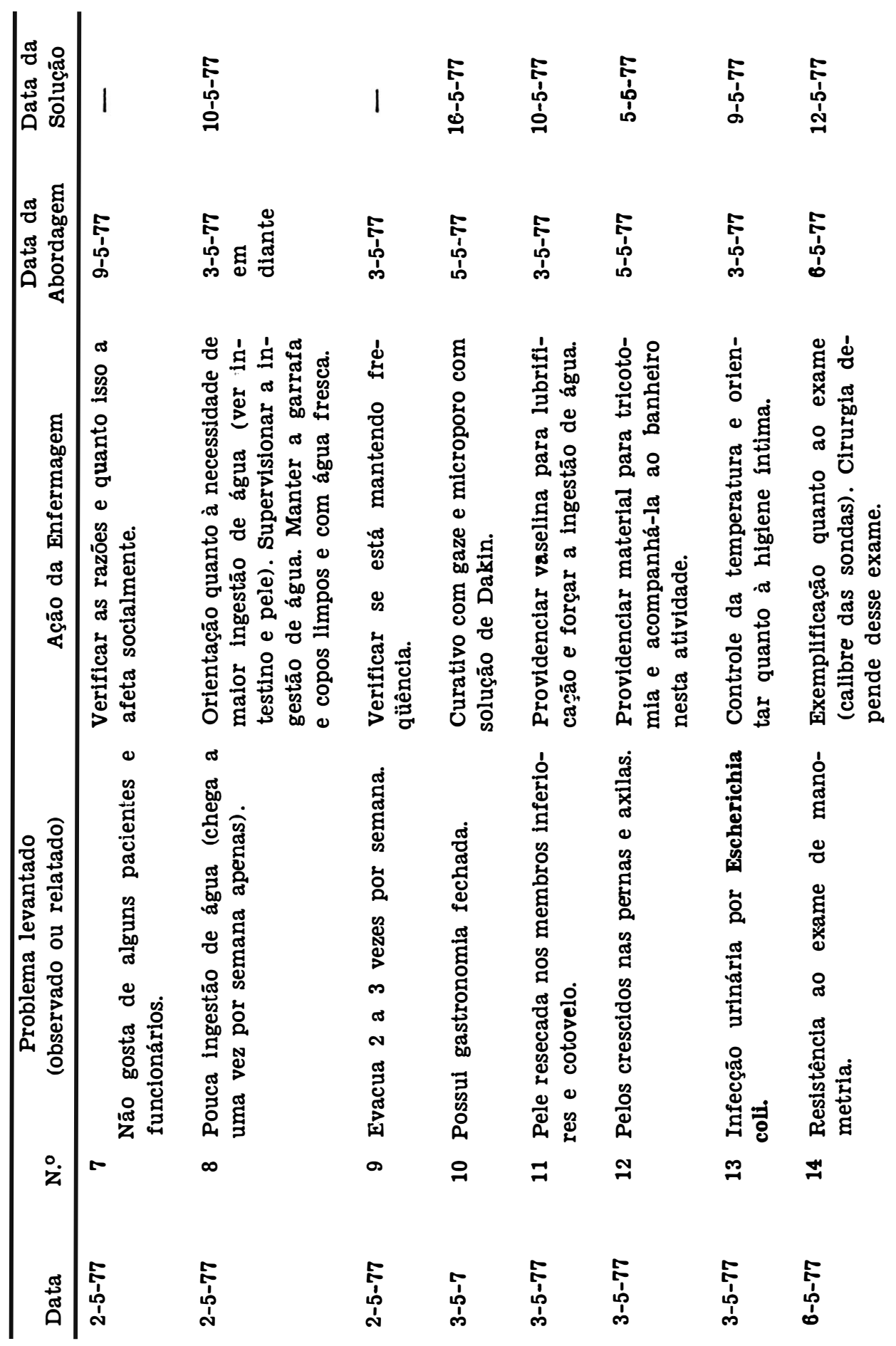


PAULA, N.S. e colaboradoras - Processo de enfermagem orientade para os problemas do paciente: iniciaçāo de ensino em fundamentos de enfermagem. Rev. Bras. Enf.; DF, 31 : 101-113, 1978.

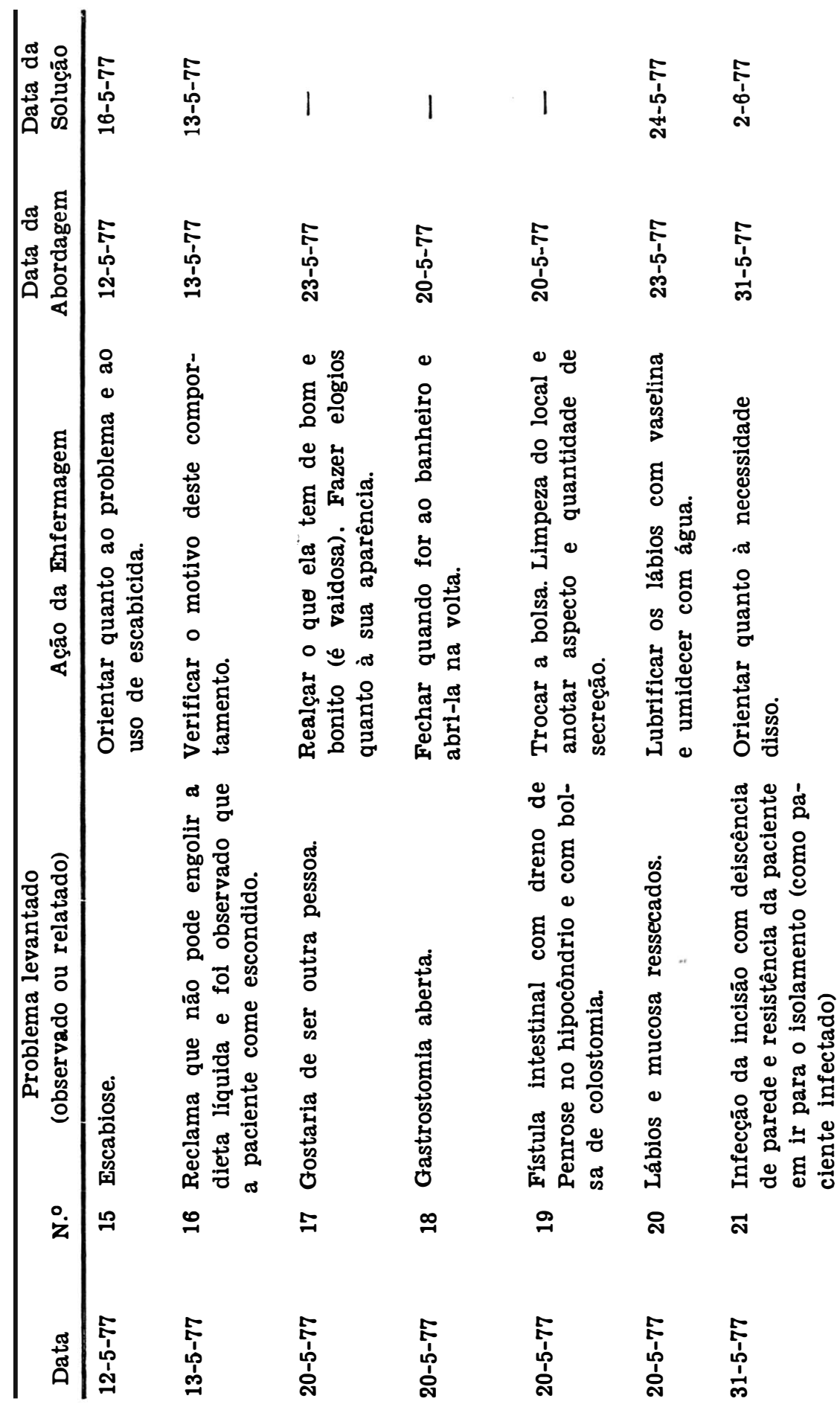


PAULA, N.S. e colaboradoras - Processo de enfermagem orientado para os problemas do paciente: iniciaçāo de ensino em fundamentos de enfermagem. Rev. Bras. Enf.; DF, 31 : 101-113, 1978.

\section{Exemplos de Plano de Cuidados}

Nome do Paciente:

\begin{tabular}{|c|c|c|}
\hline Data & Cuidados de Enfermagem & orários \\
\hline $5-5-77$ & $\begin{array}{l}\text { Controles: T., P., R., PA e Peso } \\
\text { Controle de Diurese } \\
\text { Cuidados higiênicos - Providenciar material para } \\
\text { tricotomia e vaselina para os cotovelos } \\
\text { Fazer curativos ao redor da sonda de gastrostomia } \\
\text { Verificar freqüência las evacuaçōes } \\
\text { Atençāo e orientação após a visita médica }\end{array}$ & $\begin{array}{r}8.00 \\
7.30 \\
8.30 \\
10.30 \\
7.40 \\
10.00\end{array}$ \\
\hline \multirow[t]{2}{*}{$21-6-77$} & $\begin{array}{l}\text { Controles de T., P., R., PA e Peso } \\
\text { Controle de Diurese } \\
\text { Verificar como aceita a dieta pela sonda, respei- } \\
\text { tar seu pudor e apoiá-la quanto a isso } \\
\text { Verificar se tem recebido notícias em casa }\end{array}$ & $\begin{array}{l}\text { ura } \\
8.00 \\
7.30 \\
8.00 \text { e } \\
11.00 \\
9.00\end{array}$ \\
\hline & Exemplos de Evolução do Paciente & Assinatura \\
\hline Data & Nome & Rubrica \\
\hline $5-5-77$ & \multicolumn{2}{|l|}{$\begin{array}{l}\text { Executados todos os itens do plano de cuidados, com } \\
\text { exceçāo da vaselina para os cotovelos. Apresentar- } \\
\text { se com bom estado geral. Refere ter dormido bem. } \\
\text { Ficou nervosa após a visita médica. Aceitou a gema } \\
\text { de ovo no desjejum e refere não estar conseguindo } \\
\text { engolir os alimentos. Não evacuou ontem. Elimina- } \\
\text { ção vesical normal (sic). Refere cefaléia. }\end{array}$} \\
\hline $21-6-77$ & $\begin{array}{l}\text { Abordados todos os itens do plano de cuidado. Es- } \\
\text { tava arrumando suas coisas para ser transferida } \\
\text { para Suzano. Estava alegre e dizendo que voltaria } \\
\text { em um mês. Referiu não ter recebido notícias de } \\
\text { casa, mas que escreveu para sua mãe comunicando } \\
\text { a sua transferência. Referiu ter vergonha de se ali- } \\
\text { mentar pela sonda mas que se conformava pois iria } \\
\text { se alimentar por ela só por um més e depois vol- } \\
\text { taria para fazer nova cirurgia e a sonda seria re- } \\
\text { tirada, mas nunca se acostumaria a se alimentar } \\
\text { pela sonda. Não se queixou de ir para Suzano, es- } \\
\text { tava bastante animada, não apresentando nenhum } \\
\text { sinal de tristeza ou de ansiedade. }\end{array}$ & ura \\
\hline
\end{tabular}

Assinatura 
PAULA, N.S. e colaboradoras - Processo de enfermagem orientado para os problemas do paciente: iniciação de ensino em fundamentos de enfermagem. Rer. Bras. Enf.; DF, 31 : 101-113, 1978.

\section{CONCLUSĀO}

Uma experiência da aplicação do processo de enfermagem orientado para os pacientes vem ao encontro das aspiraçōes maiores das docentes de Fundamentos de Enfermagem que em suas atividades de ensino vêm-se muitas vezes dicotomizadas em termos: estudante-paciente. Essa metodologia simples em seu contexto mais amplo já, que centra suas atenções nos problemas identificados pelo próprio estudante utilizando instrumentos e conhecimentos

\section{R.IBLIOGRAFIA}

ARADINE, C. R. and GUTHNECK, M. The problem oriented record in a $\mathrm{Fa}$ mily Health Service. The Amer. Jour. of Nursing ,74 (6) : 1108-12, June, 1974.

BROWNING, Mary - The nursing Process Practice. Contemporary Nursing Series New York. The Amer. Jour of Nursing 1974.

CARLSON, S. - A practical approach to the nursing process. Amer. Jour. of Nurs. 72 (9) : 1589-1591, Sep. 1972.

CARRIERI, V. K. and SITZMAN, J. Components of the nursing process. Nurs. Clin. N. Amer., 6 (1) : 115-124, Mar. 1971.

CIANCIARULLO, T. I. et alli - Prescriçāo de enfermagem. Experiência de sua aplicaçāo em hospital particular. Rev. Bras. de Enf., 27 (2) : 44-45, Abr../ Jun. 1974.

FRIEDLANDER, M. R. - Prescriçāo diária de enfermagem. Expçeriência para sua implantaçāo como atividade de rotina da enfermeira. Rev. Esc. da USP, (2) : 177-86, 1973.

HORTA, W. A. - A metodologia do Processo de Enfermagem. Rev. Bras. de Enf., 24 (6) : 81, Out./Dez., 1971.

- Aplicaçảo do processo de enfermagem. Rev. Esc. Enf. da USP, 9 (2) : 300-304, agosto, 1975.

HORTA, W. A. - O processo de enfermagem: fundamentaçāo e aplicação. Enf. Novas Dimens., 1 (1) : 10-16, mar./ abril, 1975.

- $O$ Histórico de Enfermagem simplificado. Enf. Novas Dimens., 2 (3) : 131-138, julho/agosto, 1976.

HORTA, W. A. - Enfermagem: teoria, conceitos, princípios e processo. Rev. Esc. Enf. USP., 8 (1) 7-15, 1974. tos adquiridos previamente em salas de aulas, proporciona um sistema de retro alimentaçāo que dinamiza o processo de avaliação do estudante. As docentes que dantes nāo possuiam instrumentos tão precisos para avaliar o estudante em funçāo de suas atividades para assistência das necessidades dos pacientes, durante 0 desenvolvimento deste trabalho no campo nāo precisariam preocupar-se com a dicotomia estudantepaciente, pois ambos eram mantidos sob controle pelo processo utilizado.

\section{CONSULTADA}

KRAEGEL. SCHMIDT, SHUKLA, GOLDSMITH, - A system of patient care based on patient needs. Nurs. Outlook, 20 (4) : 257, Apr, 1972.

LEWIS, L. - Planning patient care. Iowa, Browm, 1971.

MARRINER, An - The Nursing Process, St. Louis C. V. Mosby Co., 1975.

MITCHELL, P. H. - Concepts basic to nursing. New York, McGraw Hill, 1973.

PAIM, L. - A Prescriçāo de enfermagem Unidade valorativa do plano de cuidado. Rio de Janeiro, 1975 (Dissertação de mestrado apreesntada à Escola de Enfermagem Ana Néri, da Universidade Federal do Rio de Janeiro).

PANKRATZ and PANKRATZ - The nursing care plan: theory and reality. Supervisor Nurse, 4 (4) : 51, Apr, 1973.

PAULA, N. S. de, et alii - Ensino do plano de cuidados em fundamentos de enfermagem. Rev. Bras. de Enf., 4: 249263, ago. 1967.

ROLIM, E. de J. - Aplicaçāo de Metodologia de Enfermagem no cuidado de um paciente. Rev. Esc. Enf. da USP, 4 $(1-2): 81,95$, mar-set. 1970.

SJOBERG, D, - Unit Assigment - A patient centered system. Nursing Clinics of North America, 6 (2) : June, 1971.

VIEIRA, A. et al. - Elementos básicos para o diagnóstico de enfermagem. Rev. Paul. Hosp, 14 (4), Abr. 1971.

YURA, H. and WALSH, M. B. - The nursing process: assessing planning, implementuig, evaluating. 2nd ed. Meredith, 1973.

WEED, L. L. - Medical Records, Medical Education and Patient care. Year Book Medical Publishers. Inc. 1971. p. 297. 
PAULA, N.S. e colaboradoras - Processo de enfermagem orientado para os problemas do paciente: iniciaçāo de ensino em fundamentos de enfermagem. Rev. Bras Enf.; DF, 31 : 101-113, 1978.

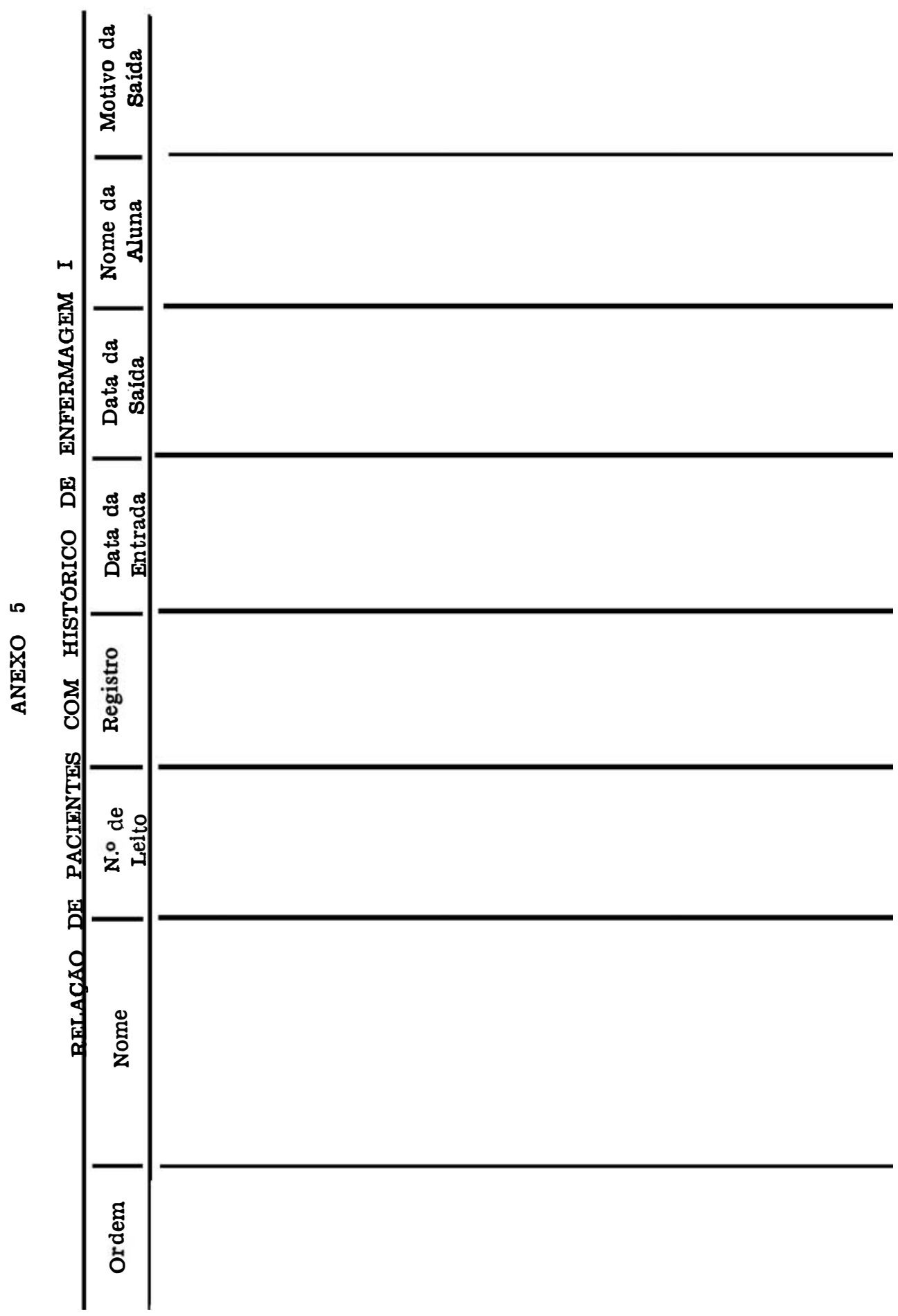

